\title{
openheart Altered gene expression in T-cell receptor signalling in peripheral blood leucocytes in acute coronary syndrome predicts secondary coronary events
}

Shin-ichiro Takashima, ${ }^{1}$ Soichiro Usui, ${ }^{1}$ Keisuke Kurokawa, ${ }^{1}$ Teppei Kitano, ${ }^{1}$ Takeshi Kato, ${ }^{1}$ Hisayoshi Murai, ${ }^{1}$ Hiroshi Furusho, ${ }^{1}$ Hiroyuki Oda, ${ }^{2}$ Michiro Maruyama, ${ }^{3}$ Yoshiki Nagata, ${ }^{3}$ Kazuo Usuda, ${ }^{3}$ Koji Kubota, ${ }^{2}$ Yumie Takeshita, ${ }^{1}$ Yoshio Sakai, ${ }^{1}$ Masao Honda, ${ }^{1}$ Shuichi Kaneko, ${ }^{1}$ Masayuki Takamura ${ }^{1}$

To cite: Takashima S-ichiro, Usui S, Kurokawa $\mathrm{K}$, et al. Altered gene expression in T-cell receptor signalling in peripheral blood leucocytes in acute coronary syndrome predicts secondary coronary events. Open Heart 2016;3: e000400. doi:10.1136/ openhrt-2016-000400

- Additional material is available. To view please visit the journal (http://dx.doi.org/ 10.1136/openhrt-2016000400).

Received 6 January 2016 Revised 9 May 2016 Accepted 24 May 2016

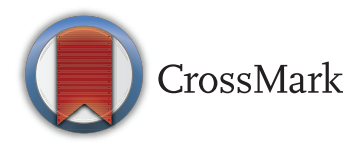

\footnotetext{
${ }^{1}$ Department of Disease Control and Homeostasis, Kanazawa University Graduate School of Medical Science, Kanazawa, Ishikawa, Japan ${ }^{2}$ Public Central Hospital of Matto Ishikawa, Hakusan, Ishikawa, Japan ${ }^{3}$ Toyama Prefectural Central Hospital, Toyama, Japan
}

Correspondence to Dr Shin-ichiro Takashima; takashin@m-kanazawa.jp

\section{ABSTRACT}

Objective: Comprehensive profiling of gene expression in peripheral blood leucocytes (PBLs) in patients with acute coronary syndrome (ACS) as a prognosticator is needed. We explored the specific profile of gene expression in PBLs in ACS for longterm risk stratification.

Methods: 30 patients with ACS who underwent primary percutaneous coronary intervention $(\mathrm{PCl})$ and 15 age-matched adults who participated in medical check-ups were enrolled from three centres. Peripheral blood samples were collected to extract RNA for microarray analyses.

Results: During the 5-year follow-up, $36 \%$ of this cohort developed the expected non-fatal coronary events (NFEs) of target lesion revascularisation (TLR) and $\mathrm{PCl}$ for a de novo lesion. Class comparison analysis $(p<0.005)$ demonstrated that 83 genes among 7785 prefiltered genes ( 41 upregulated vs 42 downregulated genes) were extracted to classify the patients according to the occurrence of NFE. Pathway analysis based on gene ontology revealed that the NFEs were associated with altered gene expression regarding the T-cell receptor signalling pathway in ACS. Univariate $t$ test showed that the expression level of death-associated protein kinase1 (DAPK1), known to regulate inflammation, was the most significantly negatively regulated gene in the event group (0.61-fold, $p<0.0005)$. Kaplan-Meier curve analysis and multivariate analysis adjusted for baseline characteristics or clinical biomarkers demonstrated that lower DAPK1 expression in PBL emerged as an independent risk factor for the NFEs (HR: 8.73; $\mathrm{Cl} 1.05$ to $72.8, p=0.045$ ).

Conclusions: Altered gene expression in T-cell receptor signalling in PBL in ACS could be a prognosticator for secondary coronary events. Trial registration number: UMIN000001932; Results.

\section{KEY QUESTIONS}

What is already known about this subject?

- Previous studies have shown that serum (or plasma) levels of cytokines or soluble proteins derived from neutrophils, platelets during the acute phase ${ }^{4}$ or at stable phase, ${ }^{3}$ after acute coronary syndrome (ACS), are biomarkers for predicting secondary major cardiac cardiovascular events (as well as biomarkers in stable coronary artery disease to predict for primary events ${ }^{67}$ ). Likewise, some genes and microRNAs in peripheral blood mononuclear cells showing specific expression profiles in ACS were demonstrated to be potential single genetic prognostic markers. $^{8}{ }^{9}$

What does this study add?

- We added a new insight that the altered gene expression profile in circulating leucocytes at the onset of ACS, particularly in the T-cell receptor signalling pathway, can be a prognosticator of secondary coronary events.

How might this impact on clinical practice?

- These findings obtained from a genetic approach might provide new insights showing that (1) acute response of the immune system, especially regarding T-cell receptor signalling on ACS, varies among patients and could characterise their prognosis of coronary artery disease, and (2) a set of specifically identified genes might not only be a prognosticator but may also provide a clue to elucidate an undetermined genetic mechanism, called 'residual risk' for atherosclerosis or vascular remodelling, beyond the established risk factors such as diabetes, smoking and low-density lipoprotein cholesterol serum levels. 


\section{INTRODUCTION}

Acute coronary syndrome (ACS) is a major cause of mortality worldwide. During the past decades, percutaneous coronary intervention (PCI) has greatly helped improve the prognosis of patients following myocardial infarction (MI). Restenosis post-stenting at the primary PCI was reduced by using the latest generation of drug-eluting stents (DESs). ${ }^{1}{ }^{2}$ In addition, oral administration of high dose of statins has been shown to reduce the secondary cardiovascular events. ${ }^{3}$ However, restenosis of the intervention site still occurs after implantation and the development of de novo lesions remains a medical problem.

Atherosclerosis, which leads to MI, is a chronic inflammation disease. Previous studies have shown that serum (or plasma) levels of cytokines or soluble proteins derived from neutrophils, platelets during the acute phase $^{45}$ or at stable phase, ${ }^{3}$ after ACS, are biomarkers for predicting secondary major cardiac cardiovascular events (as well as biomarkers in stable coronary artery disease to predict for primary events ${ }^{6} 7$ ). Likewise, some genes and microRNAs in peripheral blood mononuclear cells (PBMCs) showing specific expression profiles in ACS were demonstrated to be potential single genetic prognostic markers. ${ }^{8}{ }^{9}$ Recently, it has been reported that MI accelerates the inflammation of atherosclerotic plaques at a distance via extramedullary monocytopoiesis triggered by sympathetic nerve activation, ${ }^{10}$ indicating that peripheral immune cells may be involved in the progression of atherosclerotic plaques after MI.

However, refined prognosticating markers based on comprehensive genetic analysis have not been established. In this multicentre, 5-year cohort study based on comprehensive analysis of gene expression in leucocytes in patients with ACS, we demonstrated that altered gene expression of peripheral blood leucocytes (PBLs) during the acute phase of ACS could predict secondary coronary events such as restenosis and new lesions.

\section{METHODS}

\section{Study design}

This prospective cohort study of the gene expression profiling of PBMCs in patients with cardiovascular disease was designed to investigate gene expression profiles predictive of prognosis in patients with ACS and has been registered in the UMIN Clinical Trials Registry (UMIN000001932). This study protocol complies with the Declaration of Helsinki, the locally appointed ethics committee has approved the research protocol and informed consent was obtained from each subject. This trial included patients from three centres in Japan, from December 2007 to November 2008. Patients were eligible if they were admitted with acute chest pain suggestive of ACS and intended to undergo emergency coronary angiography. Patients with renal failure on haemodialysis were excluded. Blood samples were obtained on admission before angiography. For the present study, 30 patients who had undergone primary PCI and had available peripheral blood samples for RNA collection were included, and followed up prospectively for 5 years. Fifteen people who underwent a medical check-up in a different cohort study investigating metabolic diseases were included as control participants; the institutional review board of the Public Central Hospital of Matto Ishikawa separately approved the protocol, and written informed consent was obtained.

\section{RNA collection from peripheral blood samples and microarray analysis}

Five millilitres of whole blood were collected directly into two $2.5 \mathrm{~mL}$ PAXgene blood RNA tubes (PreAnalytiX, Hombrechtikon, Switzerland) before primary coronary angiography and were stored at $-80^{\circ} \mathrm{C}$ until RNA isolation. RNA was isolated from blood, using the PAXgene system and following the manufacturer's instructions. Briefly, PAXgene Blood RNA tubes were centrifuged, and the pellets washed and resuspended in buffer. Using the PAXgene Blood RNA Kit (Qiagen, Valencia, California, USA), lysis buffer was applied to the resuspended pellets, and RNA purification and extraction were performed using the columns. The extracted RNA was stored at $-80^{\circ} \mathrm{C}$ until DNA microarray analysis using 3D-Gene Human Oligo chip 25k (Toray Industries, Inc, Tokyo, Japan), the details of which are described in the online supplementary data section.

\section{Follow-up}

After discharge, the patients were followed up at each outpatient clinic. Follow-up coronary angiography was scheduled to be performed 6 months after primary PCI in all of the patients, whereas additional coronary angiography was considered when cardiac ischaemia was suspected by ECG, echocardiography, myocardial perfusion imaging, coronary CT and the symptoms of the patients. The primary end point of this study was non-fatal coronary events (NFEs), including revascularisation of the targeted lesion (TLR) or PCI for de novo lesions (de novo PCI).

\section{Processing of microarray data}

Hierarchical clustering of gene expression was assessed by calculating the Pearson's product-moment correlation coefficient, using BRB-Array Tools software (V.4.4.0) (NCBI, NIH, Bethesda, Maryland, USA). The data were $\log _{2}$-scaled, normalised, mean-centred and applied to average linkage clustering. The resulting dendrogram indicated the order in which the patients were grouped based on the similarities among gene expression patterns. Gene clustering data were presented graphically, and the analysed genes were ordered by the clustering algorithm, such that genes with the most similar expression patterns were placed adjacent to each other. To investigate genes differentially expressed between the groups, the class comparison tool, based on univariate $t$ tests, among the BRB-Array Tools, was used. To determine the gene pathways that were differentially 
Table 1 Baseline characteristics

\begin{tabular}{|c|c|c|c|}
\hline & Control & ACS & p Value \\
\hline $\mathrm{N}$ & 15 & 30 & \\
\hline Age, years & $64 \pm 5$ & $65 \pm 12$ & 0.84 \\
\hline Male, n (\%) & $13(87)$ & $30(100)$ & 0.11 \\
\hline Hypertension, n (\%) & $6(40)$ & $24(80)$ & 0.039 \\
\hline Diabetes mellitus, n (\%) & $0(0)$ & $15(50)$ & 0.001 \\
\hline Smoking, n (\%) & $3(20)$ & $22(73)$ & 0.001 \\
\hline STEMI (n, \%) & & $29(97)$ & \\
\hline Time from onset to balloon (hours) & & $3.7 \pm 2.9$ & \\
\hline \multicolumn{4}{|l|}{ Culprit vessel } \\
\hline LMT, n (\%) & & $2(6.7)$ & \\
\hline LAD, n (\%) & & $13(43.3)$ & \\
\hline LCx, n (\%) & & $3(10.0)$ & \\
\hline RCA, n (\%) & & $12(40.0)$ & \\
\hline Stent, n (\%) & & $30(100)$ & \\
\hline Bare metal stent, n (\%) & & $18(60)$ & \\
\hline Drug-eluting stent, n (\%) & & $12(40)$ & \\
\hline LVEF (\%) & & $58 \pm 10$ & \\
\hline Max CK (IU/I) & & $2277 \pm 2116$ & \\
\hline BNP at day $7(\mathrm{pg} / \mathrm{mL})$ & & $214 \pm 342$ & \\
\hline CRP at day $0(\mathrm{mg} / \mathrm{dL})$ & & $0.6 \pm 1.3$ & \\
\hline T-Chol (mg/dL) & 196 (167-202) & 166 (144-203) & 0.13 \\
\hline $\mathrm{TG}(\mathrm{mg} / \mathrm{dL})$ & $112(87-141)$ & $79(59-117)$ & 0.07 \\
\hline HDL-C (mg/dL) & $55(47-65)$ & $41(37-47)$ & 0.001 \\
\hline LDL-C (mg/dL) & $108(96-123)$ & $95(83-125)$ & 0.50 \\
\hline HbA1c, NGSP (\%) & $5.7(5.6-5.9)$ & $6.3(5.9-7.2)$ & 0.001 \\
\hline FPG (mg/dL) & $96(91-100)$ & $113(99-153)$ & $<0.001$ \\
\hline FIRI ( $\mu \mathrm{U} / \mathrm{mL})$ & $4.9(3.2-11.2)$ & $6.4(3.6-11.9)$ & 0.47 \\
\hline HOMA-IR & $1.1(0.8-2.6)$ & $1.8(1.0-4.6)$ & 0.14 \\
\hline BMI $\left(\mathrm{kg} / \mathrm{m}^{2}\right)$ & $23.1 \pm 2.9$ & $23.9 \pm 3.8$ & 0.47 \\
\hline \multicolumn{4}{|l|}{ Medication at discharge } \\
\hline RAS inhibitor, n (\%) & & $25(83)$ & \\
\hline$\beta$ blocker & & $6(20)$ & \\
\hline Statins, n (\%) & & $24(80)$ & \\
\hline
\end{tabular}

Data are shown as the mean \pm SD or median with IQR.

ACS, acute coronary syndrome; BMI, body mass index; BNP, brain natriuretic peptide; CK, creatine phosphokinase; FIRI, fasting immunoreactive insulin; FPG, fasting plasma glucose; HbA1c, hemoglobin A1c; HDL-C, high-density lipoprotein cholesterol; HOMA-IR, Homeostatic Model Assessment of Insulin Resistance; LAD, left anterior descending coronary artery; LCx, left circumflex coronary artery; LDL-C, low-density lipoprotein cholesterol; LMT, left main tract; LVEF, left ventricle ejection fraction; NGSP, National Glycohemoglobin Standardization Program; RAS, renin-angiotensin system; RCA, right coronary artery; STEMI, ST-elevation myocardial infarction; T-chol, total cholesterol; TG, triglyceride.

expressed between the groups, 405 pathways of the Biocarta and KEGG pathway were analysed (BRB-Array Tools). The least squares (LS)/Kolmogorov-Smirnov (KS) permutation test was used to identify the gene sets with more genes differentially expressed between the groups than expected by chance. The Efron-Tibshirani's test based on 'maxmean' statistics was also performed to identify gene sets differentially expressed. A p value less than 0.005 was deemed to indicate statistical significance. To classify the samples based on gene expression profiles, class prediction analysis (BRB-Array Tools) was performed using a compound covariate predictor incorporating genes that were differentially expressed at the $\mathrm{p}<0.01$ or $\mathrm{p}<0.005$ significance level (as assessed using the random variance t-test, using the univariate t-test values for comparison of classes with weights). The cross-validated misclassification rate was computed.

\section{Statistical analysis}

Normally distributed continuous variables were presented as the mean with SD, and variables with a skewed distribution as the median with IQR. These variables were compared using the t test (two-tailed) and the Mann-Whitney U-test, respectively. Categorical variables were presented as numbers and percentages, and were compared using the $\chi^{2}$ test for trends. Cumulative event rates were estimated using the Kaplan-Meier method and compared using the log-rank test. Univariable and multivariable stepwise Cox proportional hazards regression models (with a $\mathrm{p}$ value $=0.25$ as a criterion to enter a variable into the model) were used to identify independent correlates of the 5-year outcome. All statistical analyses were performed using SPSS statistical software (V.19) (IBM, USA). If not prescribed, a p value less than 0.05 was considered to indicate statistical significance. 
A

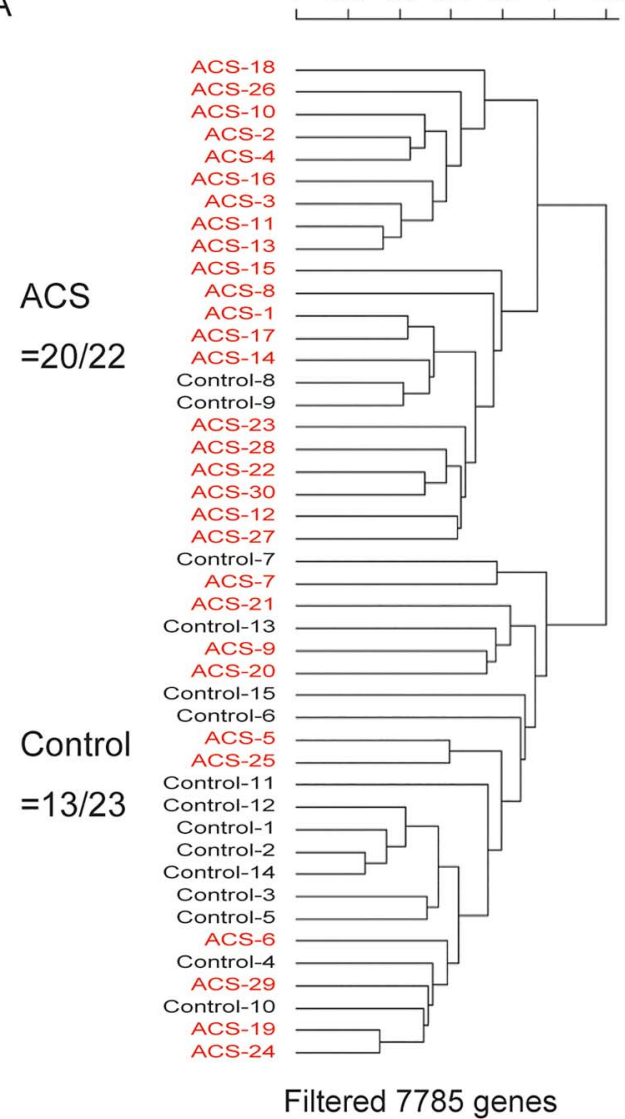

B

\begin{tabular}{c|c} 
ACS & Control \\
\hline $\mathrm{N}=30$ & $\mathrm{~N}=15$
\end{tabular}

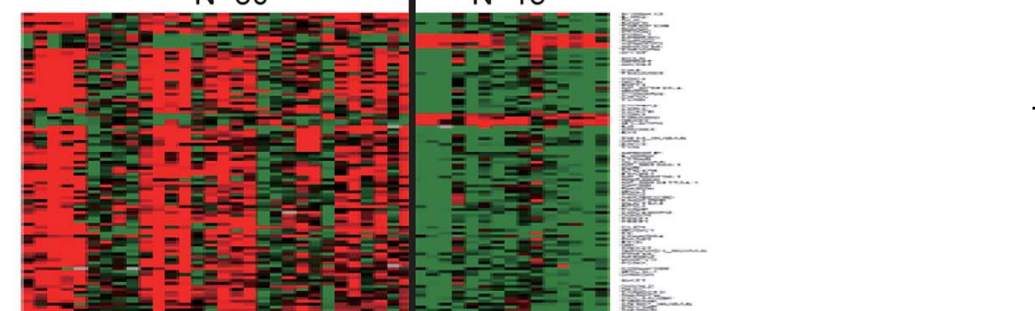

क्ष

$\stackrel{\circ}{\vec{\omega}}$

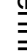

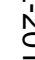

के

274 genes $(p=0.0001)$

Figure 1 Hierarchical clustering analysis of 7785 genes (genes with a log-ratio variation in the 25th centile and $>5 \%$ missing data were excluded) (A) A heat map of 274 genes extracted by class comparison analysis $(p<0.0001)$ (B) Each column corresponds to a sample, and each row represents a gene. The gene cluster data are graphically presented as coloured images; red and green indicate upregulated and downregulated genes, respectively. ACS, acute coronary syndrome.

\section{RESULTS}

\section{Patient characteristics}

The patient cohort consisted of 30 patients with ACS ( $100 \%$ males), in addition to 15 age-matched control participants ( $87 \%$ males), with mean ages of $65 \pm 12$ and $64 \pm 5$ years, respectively. Table 1 summarises the baseline clinical characteristics. The morbidity of diabetes in the ACS group was $50 \%$, and the levels of glycosylated haemoglobin and fasting plasma glucose were higher, and that of high-density lipoprotein cholesterol lower in the ACS group than in the control group.

\section{Differential gene expression profile of PBLs in patients with ACS}

As non-filtered genes (24 267 genes) may include those that are unchanged among samples, preventing efficient gene clustering due to 'noise', we filtered out such genes, using a different stringency method. Using 7785 filtered genes (genes with a log-ratio variation in the 25th centile and $>5 \%$ missing data were excluded) with a hierarchical clustering analysis and a non-supervised learning method, all of the participants were clustered roughly into two groups: the ACS group and control group (figure 1A). Among the 7785 prefiltered genes, class comparison analysis $(p<0.0001)$ was used to extract 274 genes that were significantly altered in ACS compared with the control: 228 upregulated versus 46 downregulated genes (figure $1 \mathrm{~B}$ and online supplementary table S1). We examined the pathways significantly altered in ACS, demonstrating that 19 gene sets of the Biocarta pathway were significantly changed in PBLs of patients with ACS compared with those of the control group (table 2).

\section{The clinical outcome at 5-year follow-up}

Among 30 patients, $28(93.3 \%)$ completed the 5-year follow-up (tables 3 and 4). The average follow-up period was $58 \pm 21$ months. One patient died of heart failure at 11 months after the primary PCI on ACS, through a PCI event for a de novo lesion performed 4 months before death. NFEs occurred in 11 patients $(36.6 \%)$ : TLR in 7 (23.3\%), de novo PCI in 7 (23.3\%) and both in $4(13.3 \%)$ (figure 2A). In the TLR group, DES was used in four cases $(57.1 \%)$ at the primary PCI. Table 4 shows the baseline characteristics according to the NFE. In the NFE group, multivessel disease was significantly predominant. 
Table 2 Pathways significantly altered in ACS versus the control group

\begin{tabular}{|c|c|c|c|c|}
\hline Pathway description & Number of genes & $\begin{array}{l}\text { LS } \\
\text { permutation } \\
\text { p Value }\end{array}$ & $\begin{array}{l}\text { KS } \\
\text { permutation } \\
\text { p Value }\end{array}$ & $\begin{array}{l}\text { Efron-Tibshirani's } \\
\text { GSA test } \\
\text { p Value }\end{array}$ \\
\hline \multicolumn{5}{|l|}{ Biocarta pathway } \\
\hline HIV-I Nef: negative effector of Fas and TNF & 35 & ${ }^{\star} 0.00001$ & 0.00626 & $0.025(+)$ \\
\hline Keratinocyte differentiation & 25 & ${ }^{*} 0.00014$ & 0.01083 & $0.235(+)$ \\
\hline $\begin{array}{l}\text { Chaperones modulate interferon Signalling } \\
\text { pathway }\end{array}$ & 11 & ${ }^{\star} 0.00095$ & 0.04736 & $0.17(+)$ \\
\hline$N F-\kappa B$ signalling pathway & 11 & ${ }^{\star} 0.00123$ & 0.06918 & $0.115(-)$ \\
\hline Toll-like receptor pathway & 12 & *0.00139 & 0.11089 & $0.185(-)$ \\
\hline TNFR2 signalling pathway & 12 & ${ }^{\star} 0.00165$ & 0.16091 & $0.305(+)$ \\
\hline $\begin{array}{l}\text { Acetylation and deacetylation of RelA in the } \\
\text { nucleus }\end{array}$ & 10 & ${ }^{*} 0.00323$ & 0.04009 & $0.245(-)$ \\
\hline CD40L signalling pathway & 9 & ${ }^{\star} 0.00359$ & 0.2707 & $0.265(+)$ \\
\hline Regulation of transcriptional activity by $\mathrm{PML}$ & 9 & ${ }^{\star} 0.00451$ & 0.01201 & $0.375(-)$ \\
\hline Double-stranded RNA-induced gene expression & 8 & ${ }^{\star} 0.00471$ & 0.32605 & $0.25(+)$ \\
\hline IL 3 signalling pathway & 10 & 0.00545 & ${ }^{\star} 0.00368$ & $0.275(-)$ \\
\hline Role of ERBB2 in signal transduction and oncology & 11 & 0.01509 & *0.00022 & $0.49(+)$ \\
\hline Transcriptional activation of $\mathrm{dbpb}$ from mRNA & 6 & 0.02236 & ${ }^{*} 0.00221$ & $0.41(+)$ \\
\hline NFAT and hypertrophy of the heart & 24 & 0.02685 & ${ }^{*} 0.00179$ & $0.29(-)$ \\
\hline Fc epsilon receptor I signalling in mast cells & 18 & 0.03265 & *0.0046 & $0.385(-)$ \\
\hline Multistep regulation of transcription by Pitx2 & 6 & 0.05738 & *0.0038 & $0.49(+)$ \\
\hline Growth hormone signalling pathway & 12 & 0.06599 & ${ }^{*} 0.00362$ & $0.255(+)$ \\
\hline Oxidative stress-induced gene Expression Via Nrf2 & 8 & 0.11679 & 0.74512 & ${ }^{*}<0.005(-)$ \\
\hline Protein kinase $\mathrm{A}$ at the centrosome & 7 & 0.90048 & 0.6826 & ${ }^{*}<0.005(-)$ \\
\hline \multicolumn{5}{|c|}{$\begin{array}{l}\text { A total of } 19 \text { of } 202 \text { investigated gene sets among the Biocarta pathways passed the } 0.005 \text { significance threshold of the LS/KS permutation } \\
\text { test or Efron-Tibshirani's GSA maxmean test. } \\
\text { *Denotes significant p value. } \\
\text { ACS, acute coronary syndrome; GSA, gene set analysis; NFAT, nuclear factor of activated T-cells; NF-kB, nuclear factor-kB; } \\
\text { PML, promyelocytic leukemia; TNF, tumor necrosis factor. }\end{array}$} \\
\hline
\end{tabular}

In this cohort, the levels of fasting immunoreactive insulin and HOMA-IR were lower than those in the control, while the rate of medication at discharge, including RAS inhibitors and statins, and other clinical laboratory markers, were not different between the groups. The serum level of low-density lipoprotein cholesterol (LDL-C) at follow-up was not associated with the secondary NFEs (NFE $(87 \pm 31 \mathrm{mg} / \mathrm{dL})$ vs non NFE $(100 \pm 27 \mathrm{mg} /$ $\mathrm{dL}), \mathrm{p}=0.32)$. The baseline characteristics according to the subgroup of NFE, TLR or de novo PCI are also shown (see online supplementary tables S2-1, 2-2).

\begin{tabular}{lc} 
Table 3 Outcome & \\
\hline Five years of follow-up achieved $(\mathrm{n}, \%)$ & $28(93.3)$ \\
Average follow-up period (months) & $58 \pm 21$ \\
MACE $(\mathrm{n}, \%)$ & $1(3.3)$ \\
NFE $(\mathrm{n}, \%)$ & $11(36.6)$ \\
De novo PCI (n, \%) & $7(23.3)$ \\
TLR (n, \%) & $7(23.3)$ \\
BMS (n, \%) & $3(42.9)$ \\
DES (n, \%) & $4(57.1)$ \\
Cerebral infarction ( $\mathrm{n}, \%)$ & $2(6.7)$ \\
Non-cardiac-related death (n, \%) & $5(16.7)$
\end{tabular}

BMS, bare-metal stents; DES, drug-eluting stents; MACE, major adverse cardiovascular events; NFE, non-fatal coronary events; $\mathrm{PCl}$, percutaneous coronary intervention; TLR, target lesion revascularisation.

\section{Differentially expressed genes in ACS that predict secondary NFEs}

To investigate differentially expressed genes in the NFE group, we performed class comparison analysis $(\mathrm{p}<0.005)$, extracting 83 genes among 7785 prefiltered genes (41 upregulated vs 42 down-regulated genes) (figure 2B; and see online supplementary table S3). The pathway analysis based on gene ontology revealed that T-cell receptor signalling was the most significantly altered pathway in PBLs in ACS in the later NFE development group (table 5). This gene pathway profile differed from the one that showed significant change in ACS compared with the control (table 2). Likewise, the gene pathway profile altered in ACS in the de novo PCI subgroup was different from that in the TLR group (see online supplementary tables S4-1, 4-2). To assess the predictive value of the gene sets for the NFEs, class prediction analysis, a supervised learning method based on the compound covariate predictor, was performed using different stringencies. The rate of correct classification was $60-77 \%$ (see online supplementary table S5).

\section{DAPK1 expression levels in ACS in relation to outcome}

We next investigated candidate single markers for predicting secondary NFEs. Among 83 genes extracted by the class comparison analysis, one of the most 
Table 4 Baseline characteristics according to outcome

\begin{tabular}{|c|c|c|c|}
\hline & \multicolumn{2}{|l|}{ NFE } & \multirow[b]{2}{*}{ p Value } \\
\hline & Yes (N=11) & No $(\mathrm{N}=19)$ & \\
\hline Age, years & $66 \pm 10$ & $64 \pm 14$ & 0.66 \\
\hline Male, n (\%) & $11(100)$ & $19(100)$ & \\
\hline Hypertension, n (\%) & $10(91)$ & $14(74)$ & 0.37 \\
\hline Diabetes mellitus, n (\%) & $7(64)$ & $8(42)$ & 0.45 \\
\hline Smoking, $\mathrm{n}(\%)$ & $9(82)$ & $13(68)$ & 0.67 \\
\hline \multicolumn{3}{|l|}{ Number of diseased vessels, $n$} & 0.01 \\
\hline 1 vessel & 0 & 10 & \\
\hline 2 vessels & 8 & 6 & \\
\hline 3 vessels & 3 & 3 & \\
\hline LMT lesion & $2(18)$ & $3(16)$ & 1.00 \\
\hline \multicolumn{4}{|l|}{ Stent } \\
\hline Bare metal stent, $\mathrm{n}$ & 5 & 13 & 0.26 \\
\hline Drug-eluting stent, $\mathrm{n}$ & 6 & 6 & \\
\hline LVEF (\%) & $63 \pm 10$ & $54 \pm 12$ & 0.24 \\
\hline Max CK (IU/L) & $1488(765-1940)$ & $2188(1298-3201)$ & 0.12 \\
\hline BNP at day $7(\mathrm{pg} / \mathrm{mL})$ & $102(72-370)$ & $48(33-103)$ & 0.11 \\
\hline $\mathrm{CCr}(\mathrm{mL} / \mathrm{min})$ & $62(56-70)$ & $83(52-116)$ & 0.29 \\
\hline hsCRP at day $0(\mathrm{mg} / \mathrm{dL})$ & $0.18(0.06-0.53)$ & $0.17(0.09-0.32)$ & 0.76 \\
\hline $\mathrm{T}-$ Chol $(\mathrm{mg} / \mathrm{dL})$ & $174(145-207)$ & $158(144-198)$ & 0.76 \\
\hline $\mathrm{TG}(\mathrm{mg} / \mathrm{dL})$ & $74(69-129)$ & $79(57-110)$ & 0.70 \\
\hline HDL-C (mg/dL) & $42(37-48)$ & $40(38-45)$ & 0.78 \\
\hline LDL-C (mg/dL) & $91(82-121)$ & $95(85-125)$ & 0.95 \\
\hline HbA1c, NGSP (\%) & $6.4(6.2-6.8)$ & $6.1(5.8-7.5)$ & 0.56 \\
\hline $\mathrm{FPG}(\mathrm{mg} / \mathrm{dL})$ & $108(101-121)$ & $116(99-156)$ & 0.53 \\
\hline FIRI $(\mu \mathrm{U} / \mathrm{mL})$ & $3.5(2.5-6.1)$ & $9.0(4.5-16.4)$ & 0.011 \\
\hline HOMA-IR & $0.76(0.66-1.52)$ & $2.90(1.10-6.27)$ & 0.001 \\
\hline $\mathrm{Lp}(\mathrm{a})(\mathrm{mg} / \mathrm{dL})$ & $37(32-45)$ & $26(13-42)$ & 0.27 \\
\hline BMI $\left(\mathrm{kg} / \mathrm{m}^{2}\right)$ & $23.3 \pm 3.9$ & $24.2 \pm 3.5$ & 0.53 \\
\hline \multicolumn{4}{|l|}{ Medication at discharge } \\
\hline RAS inhibitor, n (\%) & $8(73)$ & $16(84)$ & 0.64 \\
\hline Statins, $\mathrm{n}(\%)$ & $8(73)$ & $16(84)$ & 0.64 \\
\hline \multicolumn{4}{|c|}{$\begin{array}{l}\text { Data are shown as the mean } \pm \text { SD or median with IQR. } \\
\text { BMI, body mass index; BNP, brain natriuretic peptide; CCr, creatinine clearance (calculated using the Cockcroft and Gault formula); FIRI, } \\
\text { fasting immunoreactive insulin; FPG, fasting plasma glucose; HDL-C, high-density lipoprotein cholesterol; HOMA-IR, Homeostatic Model } \\
\text { Assessment of Insulin Resistance; hsCRP, high sensitivity C reactive protein; LDL-C, low-density lipoprotein cholesterol; Lp(a), lipoprotein (a); } \\
\text { NFE, non-fatal coronary event; LMT, left main tract; LVEF, left ventricle ejection fraction; RAS, renin-angiotensin system; T-chol, total } \\
\text { cholesterol; TG, triglyceride. }\end{array}$} \\
\hline
\end{tabular}

significantly downregulated (with the smallest $\mathrm{p}$ value) and meaningful genes in the NFE group was DAPK1 (see online supplementary table S3). Kaplan-Meier curve analysis showed the time course of the secondary NFEs in the three strata of the DAPK1 expression levels on admission, demonstrating that lower DAPK1 expression in PBLs on admission in primary ACS might predict secondary NFEs (figure 3). Multivariate analysis adjusted for the baseline characteristics or clinical biomarkers demonstrated that lower DAPK1 expression in PBLs emerged as an independent risk factor for secondary NFEs (table 6).

\section{DISCUSSION}

This is the first study to enrol a cohort of patients with ACS over a 5-year follow-up period in the investigation of secondary coronary events, using DNA microarray analysis. In this multicentre cohort study of 30 patients, we demonstrated by comprehensive gene expression analysis (including 24367 genes) that altered immunological gene expression in peripheral leucocytes at the onset of ACS, particularly genes involved in the T-cell receptor signalling pathway, could be useful for classifying patients according to the risk of secondary coronary events.

In all of the patients with ACS evaluated, the gene expression profile in PBLs was apparently different from that of the control participants from the medical check-up. The pathway significantly altered in patients with ACS included the Toll-like receptor pathway and CD40 ligand signalling pathway (table 2), findings that were comparable to those of previous reports. ${ }^{11}{ }^{12}$ Since the patients were included during the period 20072008, when bare metal stents or the first generation of DES, the Cypher or Taxus stent, were used for primary PCI for ACS in Japan, 30\% of patients were estimated to develop in-stent restenosis at the 6-month follow-up. In 


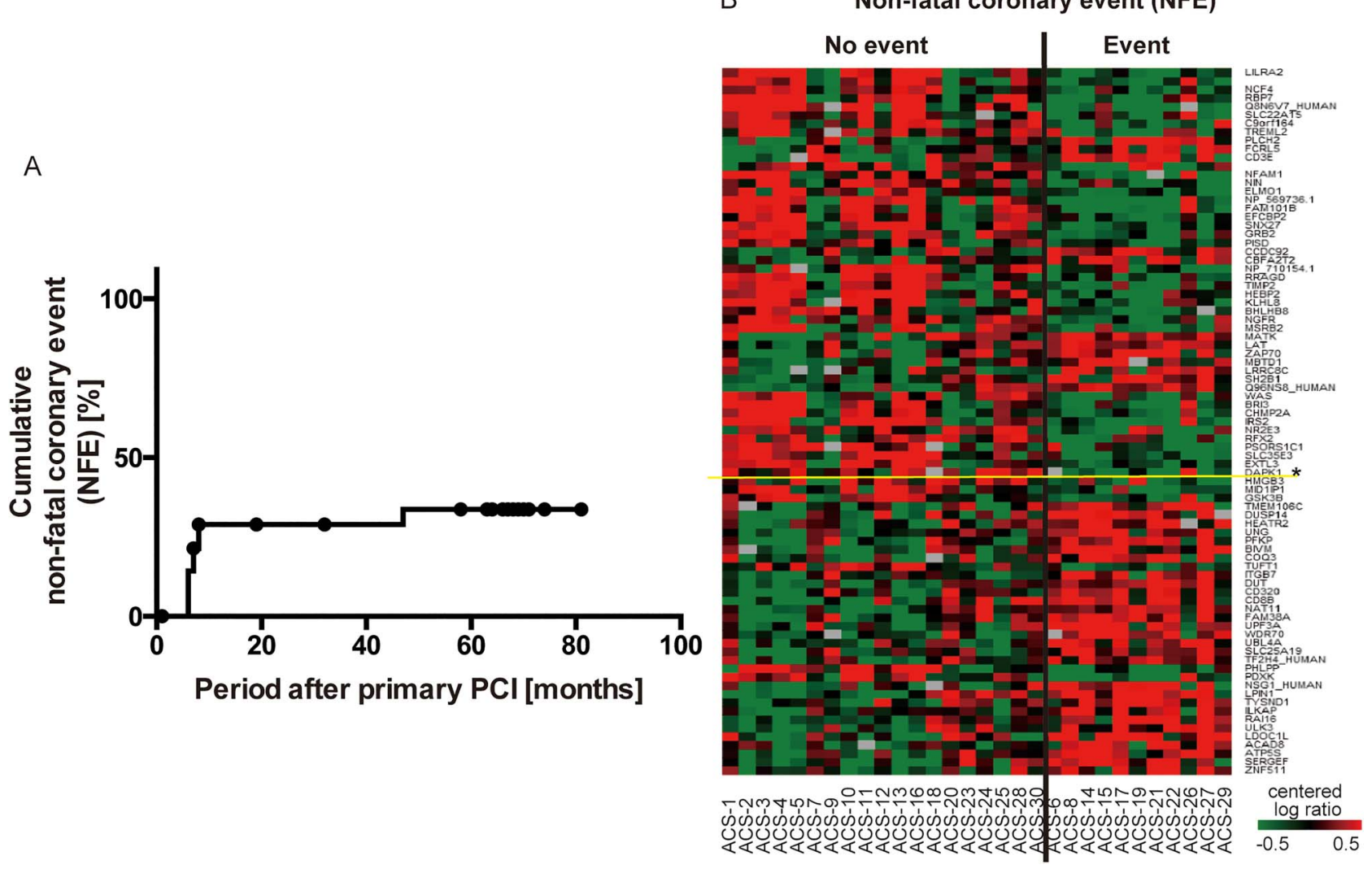

Figure 2 A Kaplan-Meier curve showing the cumulative incidence of the secondary NFE of TLR or de novo PCI during the 5 -year follow-up (30 patients) (A) A heat map of 83 genes that were extracted among 7785 prefiltered genes by class comparison analysis $(p<0.005)$ (B) Each column corresponds to a sample, which was classified according to the secondary NFE group, including TLR or de novo PCl (right side) and no event group (light side). The gene cluster data are graphically presented as coloured images: red and green indicate upregulated and downregulated genes, respectively; grey denotes unavailable data. An asterisk indicates DAPK1 as the most significantly altered and meaningful gene, of which expression was highlighted in yellow. DAPK1, death-associated protein kinase1; NFE, non-fatal coronary events; PCl, percutaneous coronary intervention; TLR, target lesion revascularisation.

this cohort, $36 \%$ of participants were subjected to TLR and/or de novo PCI, regardless of the serum level of LDL-C at the follow-up. Interestingly, the gene sets that were significantly altered in the group that developed secondary coronary events, including TLR or de novo PCI, during the follow-up, were quite different from the gene groups that changed substantially during the acute phase of ACS. Pathway analysis based on gene ontology demonstrated that altered gene expression associated with T-cell receptor signalling in ACS was a risk for secondary NFEs (table 5).

Many studies have been performed in pursuit of a new single prognosticator in peripheral blood samples. The plasma concentrations of myeloperoxidase (MPO), ${ }^{4} 13$ soluble CD40 ligand (sCD40L) ${ }^{12}$ and combination of established prognostic biomarkers, such as BNP, highly sensitive $\mathrm{C}$ reactive protein or cardiac troponin $\mathrm{I},{ }^{5}$ have been reported to be associated with the risk of death or recurrent ischaemic events, as well as first cardiovascular events. ${ }^{6}$ Because MPO or CD40L is released from neutrophils or activated platelets, both of which are key pathophysiological cells in ACS, it might be reasonable to focus on those molecules as candidate biomarkers for recurrent ischaemic events. Nakayama et $a l^{14}$ reported class A macrophage scavenger receptor (SR-A) as a predictive marker for a repeated cardiovascular event. They utilised a gene chip microarray system in patients with ACS for comprehensive analysis of gene expression in PBMCs. However, the study was performed on a small scale and was only aimed at extracting the genes most increased or decreased in ACS among a prespecified gene subset. Considering the mechanistic difference in occurrence between ACS (acute inflammation by neutrophil and thrombosis) and the secondary coronary events, including TLR or de novo PCI (chronic inflammation by lymphocytes or monocytes), the key factors for the risk prediction of secondary coronary events are not necessarily the same as the prime players in ACS. In fact, in this cohort study, SR-A was not identified as a gene predicting secondary coronary events. In a larger scale of patients with ACS, Ruparelia et al ${ }^{15}$ recently demonstrated that the differential gene expression profile of PBMC - but not PBL-at the onset of ACS, using DNA microarray analysis, made a striking contrast 
Table 5 Pathways significantly altered in the secondary NFE group

\begin{tabular}{|c|c|c|c|c|}
\hline Pathway description & Number of genes & $\begin{array}{l}\text { LS } \\
\text { permutation } \\
\text { p Value }\end{array}$ & $\begin{array}{l}\text { KS } \\
\text { permutation } \\
\text { p Value }\end{array}$ & $\begin{array}{l}\text { Efron-Tibshirani's } \\
\text { GSA test } \\
\text { p Value }\end{array}$ \\
\hline \multicolumn{5}{|l|}{ Biocarta } \\
\hline T-cell receptor signalling pathway & 26 & ${ }^{\star} 0.00001$ & ${ }^{\star} 0.00001$ & $0.25(+)$ \\
\hline Fc epsilon receptor I signalling in mast cells & 18 & ${ }^{*} 0.00005$ & ${ }^{*} 0.00097$ & $0.105(+)$ \\
\hline $\begin{array}{l}\text { Lck and Fyn tyrosine kinases in the initiation of TCR } \\
\text { Activation }\end{array}$ & 9 & *0.00006 & *0.00168 & $0.37(-)$ \\
\hline BCR signalling pathway & 15 & ${ }^{\star} 0.00009$ & ${ }^{*} 0.00325$ & $0.42(+)$ \\
\hline The co-stimulated signal during T-cell activation & 11 & ${ }^{\star} 0.00019$ & 0.0119 & $0.26(-)$ \\
\hline Nerve growth factor pathway & 11 & ${ }^{\star} 0.00027$ & 0.04891 & $0.29(+)$ \\
\hline Phosphoinositides and their downstream targets & 11 & ${ }^{*} 0.00048$ & 0.02979 & $0.36(+)$ \\
\hline $\begin{array}{l}\text { Activation of Csk by cAMP-dependent protein } \\
\text { kinase inhibits signalling through the T-cell receptor }\end{array}$ & 14 & *0.00049 & 0.01546 & $0.435(+)$ \\
\hline Granzyme A-mediated apoptosis pathway & 7 & ${ }^{\star} 0.00052$ & *0.0002 & $0.435(+)$ \\
\hline Role of Tob in T-cell activation & 10 & ${ }^{\star} 0.00223$ & ${ }^{\star} 0.00365$ & $0.495(+)$ \\
\hline $\begin{array}{l}\text { Ras-independent pathway in NK cell-mediated } \\
\text { Cytotoxicity }\end{array}$ & 12 & *0.00227 & *0.00075 & $0.345(-)$ \\
\hline HIV-induced T-cell apoptosis & 5 & *0.00305 & 0.01715 & $0.495(+)$ \\
\hline $\begin{array}{l}\text { Mechanism of gene regulation by peroxisome } \\
\text { Proliferators via PPAR } \alpha\end{array}$ & 28 & *0.00379 & 0.10998 & $0.105(+)$ \\
\hline Links between Pyk2 and MAP kinases & 14 & ${ }^{\star} 0.00415$ & 0.03066 & $0.385(+)$ \\
\hline $\begin{array}{l}\text { Angiotensin II-mediated activation of the JNK } \\
\text { pathway via Pyk2-dependent Signalling }\end{array}$ & 10 & *0.00454 & 0.0191 & $0.21(-)$ \\
\hline \multicolumn{5}{|l|}{ KEGG } \\
\hline T-cell receptor signalling pathway & 57 & ${ }^{\star} 0.00001$ & ${ }^{\star} 0.00036$ & $0.125(+)$ \\
\hline Primary immunodeficiency & 20 & ${ }^{*} 0.00001$ & ${ }^{\star} 0.00177$ & $0.375(+)$ \\
\hline Natural killer cell-mediated cytotoxicity & 54 & ${ }^{\star} 0.00003$ & ${ }^{\star} 0.00086$ & $0.12(+)$ \\
\hline Chemokine signalling pathway & 78 & ${ }^{\star} 0.00081$ & 0.01394 & $0.06(-)$ \\
\hline Fc epsilon RI signalling pathway & 32 & ${ }^{\star} 0.00219$ & 0.03961 & $0.025(-)$ \\
\hline B-cell receptor signalling pathway & 38 & ${ }^{*} 0.00262$ & 0.03951 & $0.515(+)$ \\
\hline Pyrimidine metabolism & 45 & ${ }^{\star} 0.00416$ & 0.06912 & $0.185(-)$ \\
\hline Pentose phosphate pathway & 14 & ${ }^{\star} 0.00471$ & 0.16112 & $0.48(+)$ \\
\hline Amino sugar and nucleotide sugar metabolism & 20 & 0.00903 & ${ }^{*} 0.00303$ & $0.285(-)$ \\
\hline Glyoxylate and dicarboxylate metabolism & 7 & 0.05672 & ${ }^{\star} 0.00454$ & $0.175(-)$ \\
\hline Ribosome & 77 & 0.3271 & ${ }^{\star} 0.00405$ & $0.29(+)$ \\
\hline
\end{tabular}

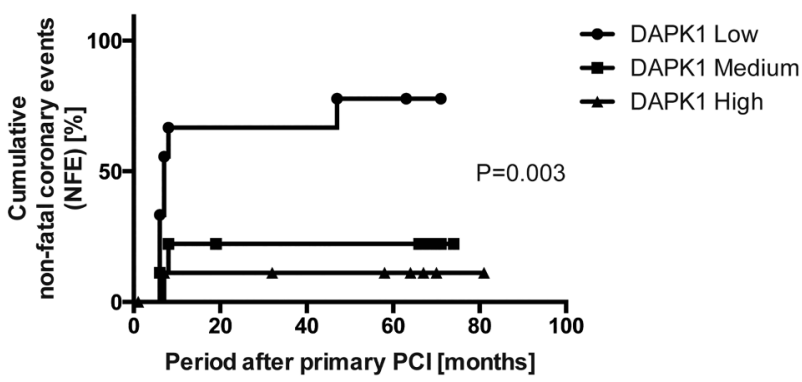

Figure 3 Kaplan-Meier curves showing the cumulative incidence of the secondary NFE of TLR or de novo PCI during the 5-year follow-up, according to the baseline expression level of DAPK1 in peripheral blood leucocytes (30 patients). DAPK1, death-associated protein kinase1; NFE, non-fatal coronary events; $\mathrm{PCl}$, percutaneous coronary intervention; TLR, target lesion revascularisation. to patients with stable ischaemic coronary disease, providing specific therapeutic targeting of key genes that could be useful for protecting acute myocardial damages. Different from these previous studies, we first utilised the gene expression profiling on ACS for predicting the secondary events. Since the progression of coronary atherosclerotic lesion or plaque instability post-ACS is associated with multiple factors including inflammation, and the risk stratification still remains fully elucidated, the approach using comprehensive gene expression may provide a new insight into a specific significant function in leucocytes, for vascular remodelling, as well as providing a prognosticator of secondary events.

DAPK is an actin-filament-associated, calcium calmodulin-dependent, serine/threonine kinase that primarily promotes apoptosis to various stimuli, including 
Table 6 Unadjusted and adjusted HRs for the 5-year NFE group

NFE
HR $(95 \% \mathrm{Cl})$

Univariable (unadjusted) Cox model

Multivessel disease (disease in 2 or 3 vessels)

Fasting IRI $(>10 \mu \mathrm{U} / \mathrm{mL})$

Diabetes

Low-DAPK1 (<median)

Multivariable (adjusted) Cox model

Low-DAPK1 (<median)
43.5 (0.260 to 7271$)$

0.025 (0.000 to 11.1$)$

2.23 (0.650 to 7.62$)$

11.3 (1.42 to 89.6$)$

8.73 (1.05 to 72.8$)$ p Value

0.150

0.236

0.203

0.022

0.045

DAPK1, death-associated protein kinase1; IRI, immunoreactive insulin; NFE, non-fatal coronary event.

Fas, INF- $\gamma$ and TNF- $\alpha,{ }^{16}$ in various cell types. ${ }^{17}$ In human carotid endarterectomy specimens, DAPK has been demonstrated substantially to express in the atherosclerotic plaque (foam cells of smooth muscle cells). ${ }^{18}$ On the other hand, DAPK has also been reported to exert antiapoptotic functions in different situations, as it was shown to suppress TNF $\alpha$-induced apoptosis by shear stress in endothelial cells. ${ }^{19}$ Lai and Chen $^{20}$ demonstrated that DAPK negatively regulates T-cell activation by selective inhibition in T-cell receptortriggered NF- $\kappa \mathrm{B}$ activation. ${ }^{21}$ Furthermore, in an acute T-cell leukaemia cell line, silencing of DAPK resulted in reduced susceptibility to Fas-induced apoptosis. ${ }^{22}$ These together may evoke a hypothesis that DAPK in circulating T-cells and endothelial cells protectively acts against vascular remodelling. In this study, DAPK1 was one of the most significantly suppressed genes in PBLs in ACS in the subgroups subsequently enduring TLR or de novo PCI. A genetic approach could enable speculation that the relatively low-expressed genes, such as DAPK1, at the onset of ACS in the subgroup of worse coronary prognosis, are essential for repair of diseased arterial endothelium but run out and poor to be recruited. These factors indicate that DAPK1 could be a candidate marker for prediction of secondary coronary events as well as being a therapeutic target.

\section{Limitations}

The limitations of this study must be recognised prior to its interpretation. First, not all of the patients underwent follow-up CAG, due to non-agreement by the patient or a hospital change in eight patients, all of whom were assigned to the group with no event. However, even after excluding these eight patients from the analysis, T-cell receptor signalling remained the principal pathway to be significantly altered on admission in patients with subsequent secondary coronary events. Second, the decision to perform TLR or de novo PCI was left to the discretion of the physician in charge. Third, this cohort, being started in 2007 or 2008, was rather old, so the frequency of use of bare metal stents for primary PCI was high $(60 \%)$, and the remaining DESs were first generation, a finding different from that observed currently. Fourth, the correct prediction rate as assessed by the class prediction analysis based on the combination of significantly altered gene sets was not satisfactory. This may be partially attributed to insufficient study data setting to control a false discovery rate with an appropriately low $\mathrm{p}$ value. Additional studies are needed to refine the prediction models. Finally, the expression level of DAPK1 in PBLs was evaluated only by a microarray from a small sized study sample as clinical outcome data, possibly causing a large variation in the results. Therefore, DAPK1 expression should be validated in another large-scaled prospective study, using quantitative reverse transcription polymerase chain reaction (qRT-PCR).

\section{CONCLUSIONS}

In this current multicentre, 5-year cohort study using comprehensive gene expression analysis, we demonstrated that the altered gene expression profile in circulating leucocytes at the onset of ACS, particularly in the T-cell receptor signalling pathway, can be a prognosticator of secondary coronary events. This finding may provide new insight regarding an undetermined genetic mechanism, called 'residual risk' for atherosclerosis or vascular remodelling, beyond the established risk factors such as diabetes, smoking and LDL-C serum levels.

Collaborators Takanori Yaegashi; Masahiko Kashimoto; Keisuke Ohtani; Tatsunori Ikeda.

Contributors ST contributed to the conception, design, data analysis and interpretation, and drafting/revision of the manuscript. SU contributed to the design and interpretation, and drafting/revision of the manuscript. KK, TK, TaK, HM, YT, HO, MM, YN, KU and KoK contributed to data acquisition. HF had full access to the data in the study, and takes responsibility for the integrity of the data and the accuracy of the data analysis. YS and MH contributed to data analysis. MT and SK contributed to the design and are the study's guarantors.

\section{Funding JSPS KAKENHI 26860549.}

Competing interests None declared.

Ethics approval The locally appointed ethics committee of Kanazawa University.

Provenance and peer review Not commissioned; externally peer reviewed.

Data sharing statement No additional data are available

Open Access This is an Open Access article distributed in accordance with the Creative Commons Attribution Non Commercial (CC BY-NC 4.0) license, 
which permits others to distribute, remix, adapt, build upon this work noncommercially, and license their derivative works on different terms, provided the original work is properly cited and the use is non-commercial. See: http:// creativecommons.org/licenses/by-nc/4.0/

\section{REFERENCES}

1. Stone GW, Lansky AJ, Pocock SJ, et al. Paclitaxel-eluting stents versus bare-metal stents in acute myocardial infarction. $N$ Engl $J$ Med 2009;360:1946-59.

2. Hofma SH, Brouwer J, Velders MA, et al. Second-generation everolimus-eluting stents versus first-generation sirolimus-eluting stents in acute myocardial infarction: 1-year results of the randomized XAMI (XienceV Stent vs. Cypher Stent in Primary PCI for acute myocardial infarction) trial. J Am Coll Cardiol 2012;60:381-7.

3. Murphy SA, Cannon CP, Wiviott SD, et al. Reduction in recurrent cardiovascular events with intensive lipid-lowering statin therapy compared with moderate lipid-lowering statin therapy after acute coronary syndromes from the PROVE IT-TIMI 22 (Pravastatin or Atorvastatin Evaluation and Infection Therapy-Thrombolysis In Myocardial Infarction 22) trial. J Am Coll Cardiol 2009;54:2358-62.

4. Baldus S, Heeschen C, Meinertz T, et al. Myeloperoxidase serum levels predict risk in patients with acute coronary syndromes. Circulation 2003;108:1440-5.

5. Morrow DA, Sabatine MS, Brennan ML, et al. Concurrent evaluation of novel cardiac biomarkers in acute coronary syndrome: myeloperoxidase and soluble CD40 ligand and the risk of recurrent ischaemic events in TACTICS-TIMI 18. Eur Hear J 2008;29:1096-102.

6. Schnabel RB, Schulz A, Messow CM, et al. Multiple marker approach to risk stratification in patients with stable coronary artery disease. Eur Heart J 2010;31:3024-31.

7. Tonkin AM, Blankenberg S, Kirby A, et al. Biomarkers in stable coronary heart disease, their modulation and cardiovascular risk: The LIPID biomarker study. Int J Cardiol 2015;201:499-507.

8. Damman P, Kempf T, Windhausen F, et al. Growth-differentiation factor 15 for long-term prognostication in patients with non-ST-elevation acute coronary syndrome: an Invasive versus Conservative Treatment in Unstable coronary Syndromes (ICTUS) substudy. Int J Cardiol 2014;172:356-63.

9. Pilbrow AP, Cordeddu L, Cameron VA, et al. Circulating miR-323-3p and miR-652: Candidate markers for the presence and progression of acute coronary syndromes. Int J Cardio 2014;176:375-85

10. Dutta P, Courties G, Wei Y, et al. Myocardial infarction accelerates atherosclerosis. Nature 2012;487:325-9.

11. Kashiwagi M, Imanishi T, Ozaki Y, et al. Differential expression of Toll-like receptor 4 and human monocyte subsets in acute myocardial infarction. Atherosclerosis 2012;221:249-53.

12. Heeschen C, Dimmeler S, Hamm CW, et al. Soluble CD40 ligand in acute coronary syndromes. N Engl J Med 2003;348:1104-11.

13. Brennan ML, Penn MS, Van Lente F, et al. Prognostic value of myeloperoxidase in patients with chest pain. $N$ Engl $\mathrm{J}$ Med 2003;349:1595-604.

14. Nakayama M, Kudoh T, Kaikita K, et al. Class A macrophage scavenger receptor gene expression levels in peripheral blood mononuclear cells specifically increase in patients with acute coronary syndrome. Atherosclerosis 2008;198:426-33.

15. Ruparelia N, Godec J, Lee R, et al. Acute myocardial infarction activates distinct inflammation and proliferation pathways in circulating monocytes, prior to recruitment, and identified through conserved transcriptional responses in mice and humans. Eur Heart J 2015;36:1923-34.

16. Bialik S, Kimchi A. The death-associated protein kinases: structure, function, and beyond. Annu Rev Biochem 2006;75:189-210.

17. Deiss LP, Feinstein E, Berissi $\mathrm{H}$, et al. Identification of a novel serine/threonine kinase and a novel $15-\mathrm{kD}$ protein as potential mediators of the $\gamma$ interferon-induced cell death. Genes Dev 1995;9:15-30.

18. Martinet W, Schrijvers DM, De Meyer GRY, et al. Gene expression profiling of apoptosis-related genes in human atherosclerosis: upregulation of death-associated protein kinase. Arterioscler Thromb Vasc Biol 2002;22:2023-9.

19. Rennier K, Ji JY. The role of death-associated protein kinase (DAPK) in endothelial apoptosis under fluid shear stress. Life Sci 2013;93:194-200.

20. Lai MZ, Chen RH. Regulation of inflammation by DAPK. Apoptosis 2014;19:357-63.

21. Chuang YT, Fang LW, Lin-Feng MH, et al. The tumor suppressor death-associated protein kinase targets to TCR-stimulated NF- B activation. J Immunol 2008;180:3238-49.

22. Raval A, Tanner SM, Byrd JC, et al. Downregulation of death-associated protein kinase 1 (DAPK1) in chronic lymphocytic leukemia. Cell 2007;129:879-90. 